
www.globaljournalseries.com; Info@globaljournalseries.com

\title{
COMMUNICATION IN ACADEMIC LIBRARIES: AN ASSESSMENT OF UNIVERSITY OF CALABAR LIBRARY TECHNIQUE IN INFORMATION SERVICES DELIVERY
}

\section{PIUS TOM UMOREN AND JULIANA NWAKAEGO AGWUNOBI}

(Received 4, October 2016; Revision Accepted 13, February 2017)

\begin{abstract}
This study surveys trends and developments concerning communication in academic libraries with emphasis on the University of Calabar Library. Three research questions were considered for investigation and these were (i) what constitute Communication in academic libraries? (ii) How do librarians engage in communication to enhance their work? (iii) What factors enhance effective and result oriented communication based on theories of communication? The study discussed the concerns of communication with regard to relationship between information and communication; purpose, types and models of communication. The study also dealt with the techniques of University of Calabar library communication with users. The study went on to appraise how academic librarians communicate in their tasks of information search, access, processing, storage and distribution to clients. The study concludes that communication engenders effective library service delivery in that it enhances the teaching, learning and research as well as community service goals of academic institutions.
\end{abstract}

KEYWORDS: Communication; information; message; intra-personal; inter-personal; theories; models; techniques, search engines; library gateways.

\section{INTRODUCTION}

Information plays a central role in contemporary society. It is a factual detail of something, situation, person or event. It is through the interaction of the factual details between persons and organizations that communication results. Thus, information, through the process of communication, can be acquired, stored, retrieved and disseminated using various and varying modes and models. Information could be messages, data, news and/or facts and where any or all of these are relayed or transmitted, will amount to communication.

It could be said that information drives communication. Academic libraries as media organizations use information to ensure dynamism towards attainment of organizational goals of teaching, learning and research as well as community service. It is in this wise that Dimkpa (1997) says media practitioners worldwide not only insist on being kept informed about all their organizational activities, but also want to provide feedback to management on the information they receive for quality decisions. The same trait applies to librarians as information practitioners in their bid to carrying out effective library services resulting from their day today interactions with library users.

\section{WHAT IS COMMUNICATION?}

Communication is a process. According to Quirk (2003) communication is a process in which people exchange information or express their thoughts and feelings. A critical appraisal of this definition will show that the central issue in communication is message or information dissemination. In furtherance of what communication is Quirk goes on to add that it is

Pius Tom Umoren, University of Calabar Library, Calabar, Cross River State, Nigeria.

Juliana Nwakaego Agwunobi, University of Calabar Library, Calabar, Cross River State, Nigeria. 
the ways of sending information especially using radio, telephone or computers. Therefore through communication people send messages and information about themselves or others as well as organizations to others. The Encyclopedia Americana (1997) describes communication as a process which also involves the production, transmission and reception of messages. Therefore academic libraries as information delivery institutions, engage in communication with their patrons in the discharge of their acquisition, processing, storage and dissemination functions.

\section{RELATIONSHIP BETWEEN INFORMATION AND COMMUNICATION}

Anything, term or expression that can give meaning will constitute information. As noted earlier, information is a fact about person, thing or event and any or all of these will explain and give understanding to an inquisitive mind.

On the other hand communication has been defined to be a process through which information can be exchanged between people and organizations. This seems the core function of academic libraries through constant interaction with users. Therefore the relationship between information and communication is that one cannot be effectively and adequately appreciated without the other. The point in this is that a person or organization will not be informed without the process of communication.

That means for communication to take place, there must be information (message), there,' must the sender (originator) of the message, there must be a receiver of the information or message, (audience) and there must be a reaction to the message received back to the sender of the message. Of course this scenario plays out in academic libraries in that from users' queries communicated to librarians, they in turn will react by sourcing for what such queries inquired. A successful access and retrieval of the information with regard to the patrons' queries will result in communication and exchange of information between the librarians and the library user-information seeker.

Gerbner, (1978), showing the relationship between information and communication postulates that communication in its most general sense, is a chain of events in which the significant link is a message. He went on to add that in this link there is a chain that connects the source that originates the message to a destination that receives and interprets the massage. Thus information simply represents a vital ingredient by which communication thrives.

The University of Calabar Library as an information storehouse discharges her information functions through an in-house organogram that links the user to information materials in her collection and other libraries' collection using information system's search engines and library internet gate ways. This in house organogram is represented below showing the different information units that are technically arranged to serve a wide range of interests with regard to information sources and materials for users' consultation. 


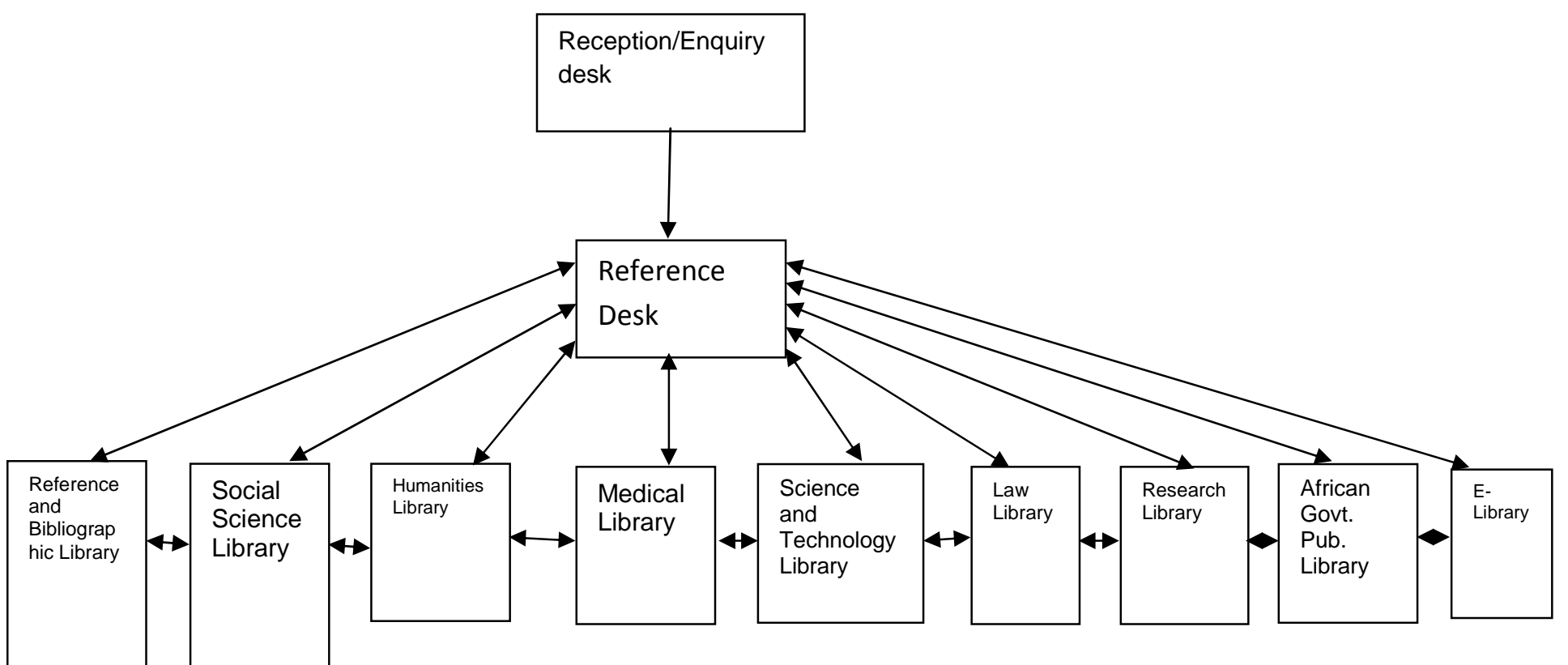

Uncial Library communication and information sourcing, retrieval and dissemination channels SOURCE: Survey tour of the Library

A fact finding visit to the University of Calabar Library to assess how academic librarians interact with users especially first timers coming to seek formation revealed the following scenario.

a. Arrival at the Reception/Enquiry desk: Here the desk officer, usually a quasi-professional or library officer, receives the new comer and subsequently directs him or her to the reference desk if the visitors intention is to source for information. But where the visitors intention is not to source for information from any of the information resources in the library collection, the receptionist will direct him appropriately.

b. At the Reference Desk: Here the visitor will interact with a professional Librarian. After listening to the visitor's query will undertake an intra-personal communication to determine where or which of the units he should direct the visitor to. If the visitors query has to do with legal information, for example, he will direct him to the Law Library where the law librarian will attend to him. If the query of the visitor indicates his interest in on-line information materials, the reference librarian will direct him to the E-library where the virtual Librarian will attend to him.

The same technique is applied to every new user of the library, where such a potential user is attended to and directed accordingly on what to do next in the course of his/her information search. A critical look at the above organogram will reveal this technical procedure of academic library communication in Unical library.

\section{THEORIES OF COMMUNICATION}

Theories are ideas or set of ideas and principles that are intended to explain things about life or the world. Theories help in the advancement and acquisition of knowledge in specific academic fields and disciplines. They 
provide guiding principles which assist in solving societal problems. In library science and practice there are theories which set out principles that aid library practice. For example Ranganathan, (1961) posited five (5) laws of library science which have to do with the book as information source which a user must have access to.

The implication of theories is that they aid research to enhance the production, acquisition and distribution of new knowledge in the different fields and academic disciplines of the society. Thus in the field of information and communication practice, theories abound to aid effective dissemination of information which equally affect library information delivery services and must be taken into account by library practitioners.

Among these theories are Ogden's and Richards' theory of meaning, theory of propaganda, psychological theory of perception and behavioural effects as well as the sociological theory of mass communication, etc, some of which are considered in this paper. These theories impact greatly on librarians as they interact with users with regard to serving them in their search for information they require.

\section{The Theory of Meaning}

This is a theory that developed general semantics as a science promoting understanding and cooperation among people. The inherent principle in this according to Ogden and Richards (1997) as well as Langers (2003) is that semantics is the study of the relations between symbols and the objects or concepts to which they refer including the changes and history of these meanings. This theory relates to information and communication practice in that there must be clarity in what message is sent for the audience or receiver to interpret correctly and appropriately. Here the librarian must be conscious of what information material that will best and explicitly serve the needy client. The subject-specialist Librarianship is geared towards this.

\section{Theory of Propaganda and Political Symbolism}

This theory relates to the political environment where practitioners are concerned with the allocation of attention and power. Being aware of the strategic significance of the control of communication, this theory was formulated to elucidate principles for "the management of collective attitudes by the manipulation of significant symbols or variables to win support", Larson, (1981). To make this theory influential/ Lassweli (2003) also describes the functions of mass communication, a vast aspect of communication, surveillance of environment, correlation of the parts of the society and transmission of socio-cultural heritage.

This theory is very relevant in the society in that it is affecting what is going on in the political scene. In Nigeria for example, the political class can do nothing without communication in a massive form. In government circles, every communication practice is employed to launder the image of government and its practitioners. The Newspaper is at work. The radio and television station owned by the different tiers of government and private organizations are not left out in the propagation of information on activities of government, organization and individuals, as the case may be. In all of these the librarian is there constantly acquiring political information materials for storage and distribution to needy political groups.

\section{The Sociological Theory of Mass Communication}

According to George (1996) some sociological theorists view mass communication as the comment of social cohesion and wholesalers of public conceptions and the models of identity. He went on to say that this consideration led to the concept of mass society where specialization of labour had been elaborated to the point that individuals cannot effectively relate to each other unless coerced. It is in this regard that the practice of communication has taken a turn, all in an attempt at forging cohesiveness through the dissemination of thought provoking informational content to specific and relevant individuals, groups and the society at large.

Here again the relevance of this theory to the practice of information and communication can be appreciated when its principles are viewed as instruments of social mobilization and conscious attention. This accords with Riesman (1950) in Budd and Ruben (1988) where he long stated that mass communication tend to channel attention/confer social status, enforce social norms, reinforce existing attitudes and serve as opinion leaders in different areas of life in different ways. It is the combination of the different human traits that mass media came into being to cater for communication in a massive 
scale, hence the use of print and electronic media in communication.

\section{PURPOSE OF COMMUNICATION}

Every act of communication has a purpose. It is this purpose that shapes the pattern of transmission which in turn will form the basis for measuring the effectiveness of the information communicated. Given that the practice of communication is at times multifaceted, the extent of success in communication with people will determine the success or otherwise in organization and/or administration. Thus in the context of academic libraries, the purpose is embedded in the statutory and enabling instruments of these institutions, that is the law that empowers the establishment of the Library. This includes the purpose of acquiring information resources, the purpose of processing them, the purpose of storing them and the purpose of distribution of the information.

\section{TYPES OF COMMUNICATION}

Communication may be simple or multiple, specific or general, may call for action, meditation, support for a course or may give approval. Academic librarians engage in all of these types of communication. These depend on the user and his intention. It is in consideration of all these that experts come up with four major types of communication.

According to Arikpo (2002) communication begins with the intra- personal through the interpersonal and group (or organizational) levels to mass communication. Explaining the different types, he says intrapersonal communication, the lowest level of communication takes place within an individual where interpretation of massage intuitively generated, is personally carried out.

In academic library this type of communication will result in the librarian when he is considering traits that characterize human information interaction. Given the diversity in information content of academic libraries, librarians must engage themselves in intrapersonal communication by mentally determining what information material to give the client based on his query.

Interpersonal type of communication is that which relates to interactions between persons. Arikpo says there must be an initiator, a channel, a receiver and feedback, interaction in a face-to-face format. This play out in academic libraries where a user walks into the library and interacts with a librarian through his queries.

Group (or organizational) communication is that which takes place between an assemblage of people. Here communication will result from international relationships amongst members of a group or organization. This is where mass communication processes are employed. Academic libraries engage in this type of communication through installation of library information systems as well as internet gateways to serve the mass of students seeking information at the same time.

Mass communication involves a nonface-to-face contact and interaction. It uses mass media in an impersonal and informal way. It is highly structured with specific persons performing specific functions to aid information dissemination to receivers no matter how vast and varied they may be. In this direction therefore, academic librarians perform their duties communicating through the use of library information systems, that is, the ICT, in every facet with information seekers who come to make use of the library. Thus, with application of the ICT, librarians can access, process, store, distribute and disseminate information of choice in relation to client's needs.

\section{MODELS OF COMMUNICATION}

A model is an artificial representation of a thing that is real. Such presentation can be graphical, for example, and organogram of an establishment. Models are useful because they provide an opportunity for people to analyze manifest things leading to improvements.

In communication there are various types of models and theoretical networks which guide the practice of information acquisition, processing, transmission and storage. Among these models are the Aristorian model (which is regarded as the oldest), Barlo's model, the mathematical model of Shanon Weaver, as well as the Shanon Schram model. In all these models, six common features of communication can be identified. These are:

- The purpose for the communication

- The communicator (originator or source of the message or information)

- The content: This is what the originator transmits. It could be a message, an idea, feeling or information about values, beliefs, attitudes, policies, questions or problems 
- The medium: This could be through the spoken word (language); it could be pictorial showing personal images or other objects, it could be choreographic representation of traditional dances etc. It could also be through written or printed words. For example, letters, circulars, bulletins as well as other print materials carry one message or information or another.

- The channel: This is anything that aids the transmission of message(s) or information. The special feature of channel of communication is that it can take any format. It can be upward, downward or horizontal. For example, in an official and formal settings, responsibility flows from bottom of the hierarchy upwards while command flows from the top downwards.

In academic libraries, communication channels can be multifaceted for instance in the University of Calabar Library academic Librarians and other staff communicate breaking departmental and sectional boundaries to source for and retrieve information to satisfy clients. Thus, the Social Science Librarian can reach out to his Law library counterpart for information on behalf of a client he is attending to instantly.

- The Audience (Receiver): This is the person or group that receives the content of the communication process. It is the audience that is the target of every message or information. How it receives, understands and interprets the message will however depend on certain factors that may affect the various elements highlighted including the audience. Such factors include quality of the message, competence of the sender, clarity of the medium, directness or exactness of the channel as well as ability or receptibility status of the audience. $\mathrm{AH}$ these affect and will definitely determine the effectiveness of communication.

It is in recognition of these factors that academic libraries are organized in manner that would aid users move straight to appropriately designated section with information materials relative to user needs. Thus a user requiring legal information will be directed straight to the Law library where he will be served better and his information quest satisfied.

\section{TECHNIQUES IN UNICAL LIBRARY COMMUNICATION WITH USERS}

Certain factors govern the organization of communication to make it effective. These factors include participant factors, message factors, channel factors as well as proximity factors. All these factors affect and involve the librarian in academic libraries. Of course the librarian is a participant, dealing with information content and materials (message), relaying same through appropriate channel (s) after noting the nature of the massage and where the massage is meant to be distributed to talking about proximity factor. A careful appraisal of the factors with regard to academic librarians duties showed that there is collaborative interactions between the librarians themselves as well as the clients who through the library for their diverse information needs.

\section{Participant factors}

This has to do with interaction between the originator and the audience or receiver who in communication are human beings. As human beings they share certain characteristics in common especially while communicating. Therefore their skills and techniques in communicating with one another will depend on their encoding and decoding abilities. While the message originator requires encoding skills to put his information across, the receiver must have appropriate decoding technique to interpret the message sent to him. These affect communication in one way or the other. Librarians in academic libraries must of necessity poses these encoding and decoding abilities to be able to serve clients better.

\section{Massage factors}

A number of factors are involved here. These include message codes which are symbols used in communication. Such codes can be verbal, gestures, sculpture, writing, etc. depending on the type of message and the appropriate communication technique. Another factor is message treatment. The way the message originator communicates a confidential message is different from the way he will handle a message meant for the public, for instance. On the other hand, the receiver of a confidential information will handle it differently from a nonconfidential information. These determine how communication messages are treated. They also determine the techniques for such communication. Although they may be no confidential information in academic libraries, 
there are however reserved materials which are treated with utmost care. Librarians in sections housing such materials treat them exclusively with extra security measures attached to their access and usage. For example, information materials in the Law Library section of University of Calabar Library are not borrowed out for home, private study, a condition not applicable to materials in the Social sciences or Humanities Libraries.

\section{Channel factors}

These also determine how communication can be effected. As a feature of communication process, channel factors would surely dictate what technique to employ to achieve effective communication. For example, if an organization is a formal type, information regarding command must emanate from the top of the hierarchy down the rank and file. But in academic libraries, communication with regard to information sourcing, access, distribution as well as storage can emanate from any direction through any but appropriate channel to get to the objective. Thus in University of Calabar Library, clients employ both formal and informal channels and methods of communication at their disposal to relate with librarians.

\section{Proximity factors}

To communicate effectively proximity on the part of the originator (sender) of the message with regard to the receiver or audience must be taken into account. The implication is that keeping similar things apart cannot enhance communication. Thus, the purpose of the sender of the message, the medium to be used and the audience must be approximated so that appropriate communication skills could be employed for effective communication of the message intended. For example, a communication that would involve a large mass of people in an equally large mass of geographical area must employ appropriate mass communication technique of say radio or television for effective information dissemination and distribution.

In academic libraries the proximity factors may be appraised in two ways viz: (i) clients physically present at the time of information sourcing and (ii) client relaying their requests outside the library. For effective communication to take place, Librarian, must employ the skill that will best enhance the discharge of their duties. Therefore, external and non-physical clients can be reached through any aspect of the information systems available in the library. In the University of Calabar Library academic librarians in charge of reference services employ the Selective Dissemination of Information (SDI) techniques to serve such clients.

\section{SUMMARY}

It has been shown in this paper that communication is not only limited to exchange of information but it involves all other forms of interactions including the sharing of feelings, ambitions, desires and knowledge, etc, through appropriate communication processes or media. It is also noted that the type of information to be disseminated will determine the type of communication process, model and technique to be employed for effective communication. The theories of communication examined herein brought to the fore the different principles that anchor effective information dissemination culminating in the development and institutionalization of the use of the print (books, Newspapers, magazines) as well as the electronic (radio, television, satellite) media in information acquisition which also effect librarians in academic institutions. Thus for academic librarians to perform optimally, must be effective in information and communication practice in their day to day functions. In fact, like the lawyer would claim of everything, a librarian must have knowledge of every information material in his custody.

\section{CONCLUSION}

There are intrinsic facets to communication that make it unique and practicable. One of such facets is that it is a symbol of unity. It fosters and engenders close relationships through information contents disseminated to common interests and aspirations. It therefore means that communication, especially mass media, can promote cultural identity as well as homogenization in a set up say, a country like Nigeria with multicultural pluralism. From the foregoing assessment, there is a very strong correlation between communication and library service delivery. Therefore with the tripathied functions of the mass media to inform, educate and entertain, communication can be viewed as academic library's process, veritable means of social mobilization of peaceful and harmonious 
co-existence. Its functional effects are sources of enhancement of the teaching, learning and research as well as community service of academic institutions in particular and the polity in general.

\section{REFERENCES}

Arikpo, A. B., 2002. Communication and Mass Media in community Development, University of Calabar: Department of Adult and Continuing Education.

Dimkpa, P., 1997. Management in Nigeria Lagos: org. Communication Consults.

Encyclopedia Americana., 2003. (International Edition) Connecticut: Grolier Incorporated.

George, I. M., 1996. Understanding and Managing Organization Behaivour. Menlo park: Adison Wesley.

Gerbnor, G., 1978. The Analysis of Communication Content: Development in scientific Theories Computer Techniques. Krieger: Prentice-Hall.

Langer, S., 2003. Philosophy in a in New Key (3rs ed.) USA: Grolier incorporated.
Larson, C. U., 1981. Communication: Everyday Encounters. Waveland Press.

Lasswell, H., 2003. Theories of Propaganda and political symbolism in Encyclopdia Americana Grolier Incorporated.

Ogdon, C. K and Richards., 1997. The Meaning of Meaning (4th ed.) USA: Grolier Incorporated.

Quirk, R., 2003. Longman Dictionary of Contemporary English. London: Longman Publishers

Ruben, B. D., 1988. Communication on Human behaviour New York. Macmillan.

Ranganathan, S. R., 1961. The five laws of Library Science. London: Edward Goldston. 